\title{
EEN KUUB THEE OP EEN PALLET
}

In het Aziatisch Paviljoen wordt de bezoeker van het Rijksmuseum tegenwoordig verrast door een installatie, van een hedendaagse, spraakmakende Chinese kunstenaar, Ai Weiwei. De titel(s) die het werk heeft meegekregen bij de verschillende musea en galeries die het hebben aangekocht of tentoongesteld, zijn op verschillende wijze beschrijvend: Ton of tea, zoals het tot nu

U toe meestal heeft geheten, wijst op de kubieke omvang of gewicht; Tea brick, U zoals het Rijksmuseum het noemt, heeft betrekking op de bewerking - de thee is geperst.

De gebruikte theesoort, Pu Er, is een type thee dat donker is, dus niet 'groen', maar die toch niet tot de 'zwarte' theesoorten wordt gerekend (zoals Oolong, de bekendste zwarte Chinese thee).

De smaak van Pu Er is bitter en sterk, de thee leent zich dan ook niet voor het 'recreatief' drinken in grote hoeveelheden, maar heeft vooral medicinale toepassingen. Bovendien wordt de thee hogelijk gewaardeerd om zijn kwaliteiten als digestief, na een zware maaltijd.

Commercieel wordt de thee meestal geperst geproduceerd in platte, ronde cakes, of in een meer ' $k$ nol'-achtige vorm, ongeveer zoals een tegenwoordige zogenaamd wilde perzik, met een holte aan de bovenkant, en dan stuk voor stuk in met lovende teksten bedrukt zijdevloei gewikkeld, maar 'losse' Pu Erthee wordt ook wel verkocht. Exclusief voor het keizerlijk hof werden vroeger ook grote, ronde knollen Pu Er-thee geproduceerd, waaraan de thee zijn tweede naam, Rentou-cha (Manshoofd-thee), te danken heeft.

Zijn meest bekende naam ontleent de thee echter aan de plaats van herkomst (oorspronkelijk, althans; tegenwoordig wordt de populaire thee ook in andere streken geteeld).

$\mathrm{Pu}$ Er, het traditionele centrum van de theehandel, is een prefectuur in het verre zuidwesten van Yunnan - de op zijn beurt weer meest zuidwestelijke provincie van China, aan de 'buitenkant' grenzend aan Burma en Laos, en binnenslands aan de provincie Sichuan. Yunnan heeft etnisch gezien de meest gevarieerde bevolking van heel China: volgens de Times Atlas of China telt de provincie maar liefst 28 verschillende nationaliteiten, ('minderheden' in het Chinese spraakgebruik) waarvan enkele zich vanouds speciaal hebben toegelegd op de teelt en verwerking van thee.

Geperste thee is vooral gebruikelijk in de vorm van 'theetegels', die ook in Nederland wel bij gespecialiseerde koffie-en-thee-winkels werden en worden verkocht. Ze zijn aantrekkelijk door hun reliëf-decoratie, met aan de ene zijde een afbeelding, en tekst in karakters (afb. 2), en aan de andere kant een simpele hokjesverdeling, waarschijnlijk om de portionering van de juiste hoeveelheid thee te vergemakkelijken. Ikherinner me reen kortstondige rage $8: 12 \mathrm{Am}$ 


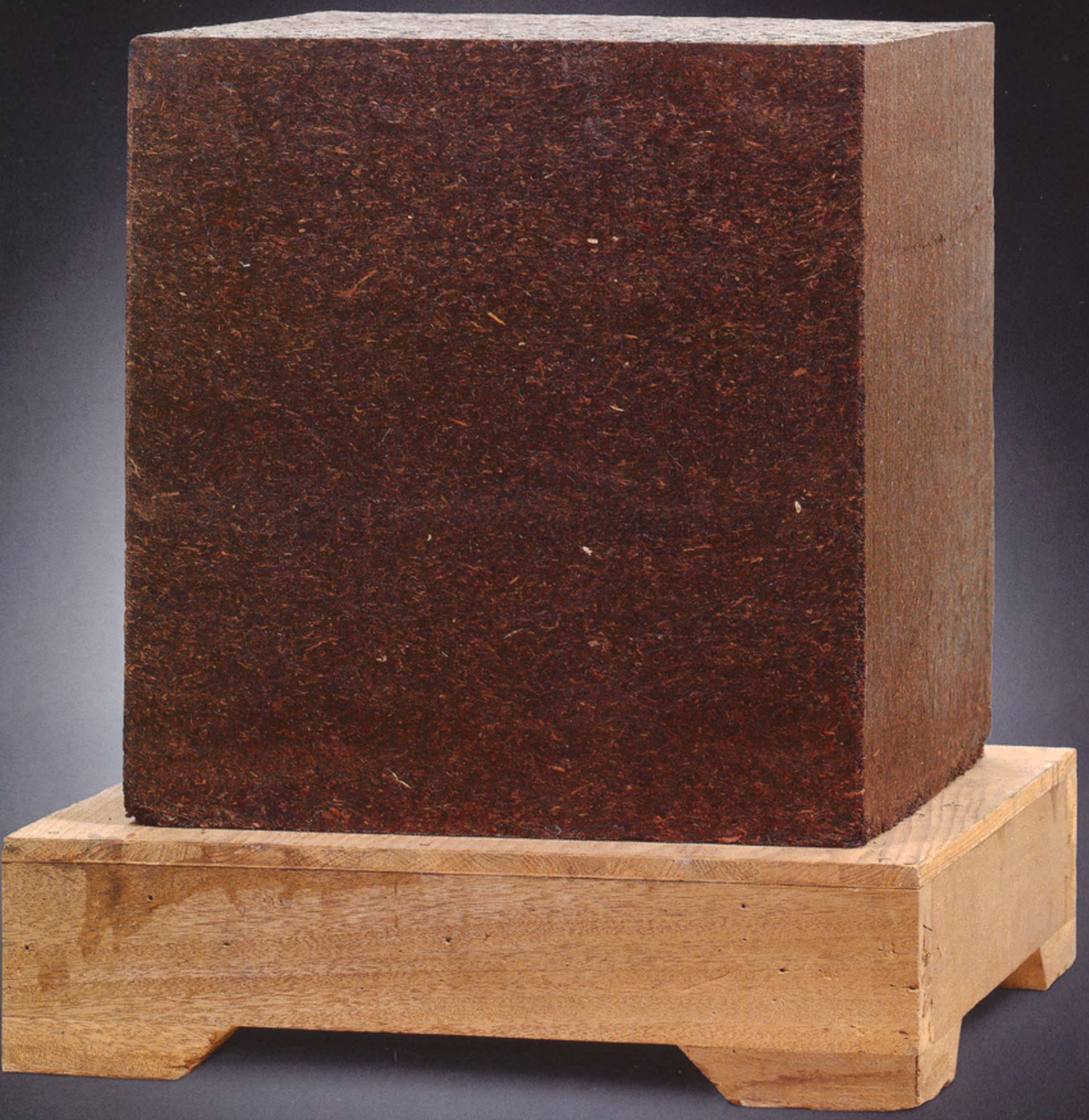


Afb. 1 (pag. 48)

Ai Weiwei (geb. 1957), Tea brick, geperste $\mathrm{Pu}$ Er-thee, houten sokkel, h. $49,8 \mathrm{~cm}$., China, 2006, Rijksmuseum, inv.nr. BK-C-2013-11. Bruikleen van de Triton Foundation, 21 maart 2013. (C) Weiwei Ai. Fotografie: Dominique Provost, Brugge

Afb 2

Theetegel. De afbeelding toont een triomfboog met drie doorgangen, op een betegeld terras. Aan weerszijden staat een theestruik in een decoratieve kuip, met een stèle erbij. Het opschrift vermeldt dat de tegel is gemaakt door de Zhongguo Chaye Gongsi [de Chinese Tea Company], en afkomstig is uit het Zhao Li Qiao Zhuan Cha Chang [het Brick-tea Depot bij de Zhao-Li brug]

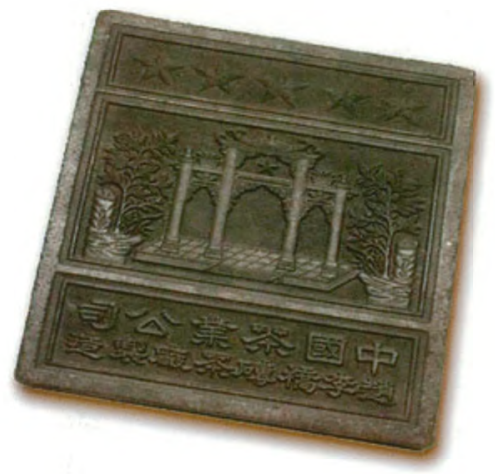

van theetegels als verjaardags- of Sinterklaascadeautje, in de late jaren '50, dankzij de rubriek Tip van Roos van Jeanne Roos in het Parool, maar volgens mij werden de toen zo grif gekochte tegels alleen uitgestald, en maar zelden gebruikt om een potje thee van te trekken (veel te bitter!)

In andere installaties, zoals de verschillende versies van Tea-house, uit 20092011, heeft Ai hetzelfde materiaal toegepast: 432 tot grote blokken geperste thee, in dit geval in ongeveer (dikke) baksteen-verhoudingen, en driehoekige blokken, maar daar zijn vervolgens gigantische 'Monopoly-huisjes' mee gestapeld. Onze kubus is de tot het uiterste geminimaliseerde versie hiervan, één gelijkzijdig blok, met als enig extra element de gestileerde houten 'pallet' waar de kubus op rust, en die mogelijk refereert aan de grootschalige handel in thee in VOC- en EIC-dagen - je ziet het blok zo op zijn pallet op een kademuur staan.

Helaas is in het Rijksmuseum het theeblok veilig in een eigen glazen vitrine geplaatst, waardoor het publiek de olfactorische sensatie - behorend bij in één ruimte verkeren met 'een ton thee' - wordt onthouden.

- Ellen Uitzinger heeft een grafische kunstopleiding aan de voorloper van de Rietveld Academie afgerond, en (jaren daarna) een studie Sinologie in Leiden. Zij gaf daar later het college 'kunst en materiële cultuur van China', en maakt tegenwoordig deel uit van de redactie van Aziatische Kunst. Naast kunst, gaat haar interesse in het bijzonder uit naar (keizerlijk) ritueel, en eetcultuur.

\section{Literatuur}

'P'u-erh tea', Bulletin of Miscellaneous Information, Royal Gardens, Kew (1889), pp. 118-20, 139-42.

Frederick J. Simoons, Food in China: A Cultural and Historical Inquiry, CRC Press, Boca Raton, Florida, 1991, pp. 446-8. 